\title{
How to guide female college students to set up the correct concept of love and marriage
}

\author{
Yu Liao \\ City College of Wuhan University of Science and Technology, Department of Business Management, \\ Wuhan, China \\ E-mail: tomliao-898@163.com
}

Keywords: Colleges and universities, Female college students, Marriage concept

\begin{abstract}
The view of love and marriage is not fixed, and people's view of love and marriage is not the same at different times. The formation of the concept of love and marriage has its complicated social and historical factors as well as individual subjective factors. With the rapid development of China's economy, people's marriage concept has changed dramatically. Female college students in China are also affected by this social change. In the search for a mate, the problem of choosing a partner is also widespread. Based on the analysis of the influencing factors of the view of love and marriage, this paper discusses the reasons for the change of the value orientation of Chinese people's view of love and marriage, and puts forward the measures to guide female college students to establish the correct concept of love and marriage.
\end{abstract}

\section{Introduction}

Concept of love and marriage refers to the opinions and attitudes of the root of the love, marriage and sex for the men and women including a series of issues and attitudes, such as, including the nature of love, standard for choosing friends, morality and responsibility for love and marriage. concept of love and marriage is an important part of the outlook on life, it directly affects the behavior orientation and mating behavior of youth in the value of love and marriage, it plays an important guiding role, and even influence the development of his life and happiness.

In recent years, due to the influence of the social and economic development and the diversity of values in our country, college students 'views and perceptions of love and marriage have undergone great changes, and many new phenomena have emerged that have never existed before. It has aroused widespread concern in society and institutions of higher learning. What kind of view of marriage and love college students hold not only directly affects their physical and mental health, makes it an excellent model of marriage and love, but also promotes the construction of a harmonious society in China.

\section{The Change of the View of the Contemporary Marriage and Love}

Some young people in today's society generally have erroneous views on marriage. Some people want to change their fate by marriage, and some think of marriage as a material exchange. Because of this, there are endless reports on the "high price bride price" in the society. In addition, such as cars, houses, accounts, etc., the chaos of marriage prices is paid attention to by public opinion. In fact, marriage should be based on emotional identity and value recognition, such a marriage can last.

Today's "blind date" has indeed changed a lot compared to the past, especially in the city, offline venues, social media, dating websites, television dating programs, etc.. It is a vast platform. However, after "blind date" became a business, there was a lot of chaos. The chaos of marriage and love mainly focuses on dating websites, dating programs, local evil customs, young couples 'emotional discord, and the protection of the legal rights and interests of marriage and childbirth. The marriage intermediary market is chaotic, the marriage agency that has transferred to the Internet, and the TV dating program that has become popular and purple, some of which are 
seriously inaccurate, and some of which have serious deviations in orientation, so that the behavior of the marriage agency and the fraud of marriage has been noisy for a time.

Recently, the once-despised "Chinese-style blind date" seems to be on fire again. In the blind date program, those well-dressed parents are picking on the blind date object, and they are no different from buying and selling goods. The clearly priced for love makes it almost impossible to see anything that concerns the feelings of men and women. It is not that we do not take into account household registration, income, real estate, or academic qualifications, but if we only consider these, we ignore people's morality, literacy, ideology, and pursuit. The marriage relationship established on the basis of buying and selling is certainly not firm, and once there is a trend, Will soon be wiped out. The concept of marriage and love is a reflection of values and outlook on life. Values and outlook on life are not correct, and the concept of marriage and love must be wrong. From a failed marriage, you can always see the selfishness and greed that can be found in various "blind date price lists"or "blind date contempt chains".

\section{Influencing factors of female college students 'views on marriage and love}

\subsection{Personal factors}

The first is education. The pursuit of free love, spiritual pleasure and satisfaction is more important for a college student with higher education. The vast majority of female college students choose free love. Moreover, female college students with knowledge and culture usually have better analytical ability. They have clear goals and clear requirements when choosing marriage objects. Second, most of the "post-90" female college students are only children. They are active, cheerful, and motivated. They have high psychological expectations for themselves, desire to Excel, and hope that others will envy them. This makes it easy for them to form self-centered, selfish, regardless of other people's feelings and other bad psychology. These psychology cause them to be self-centered and ignore each other's feelings when they are in love and marriage.

\subsection{Family factors}

The first is the material conditions of the family. Children who lack basic material security are easily tempted by the external environment. After they grow up, they may have more money worship thoughts or vanity. Of course, there are also poor and simple children. Children who grow up in situations where the family's material conditions are very superior are usually carefree, receive good education, and can form a correct outlook on life and values. Of course, in good family in material conditions, if parents coddle their children, it is easy for them to develop luxury, arrogance, and other personalities. When dealing with marriage and love objects, it is easy to be self-centered without regard to other people's feelings; The second is the family spirit atmosphere, which mainly includes the values of parents, the concept of marriage, the state of marriage, and the family atmosphere. Parents 'values are very important to influence their children. Parents are the children's first teachers. From the birth of children to the gradual development of values, are inseparable from the parents in daily life in the subtle education and influence. Whether the relationship between the parents is harmonious or not, whether the family atmosphere is harmonious will affect the children: the children who grow up in a harmonious family atmosphere are optimistic and cheerful, full of hope and passion for life, and are relatively gentle and modest in their love objects; Parents who lose and even have domestic violence will leave a shadow on their children's hearts, and then fear the marriage and family, unable to believe that they can have a harmonious and happy family; The third is the parents 'lack of education for their children in the marriage and love education. These deficiencies make female college students do not know how to deal with the problem of marriage and love, and do not know how to protect themselves when faced with temptation.

\subsection{School factors}

The liberal humanistic environment and the beautiful campus environment of the university all help college students relax their minds and bodies, which is conducive to the occurrence of college 
student romance to a certain extent. The motivation of college students to choose to fall in love is influenced by others. The frequent appearance of campus love songs and love videos on campus also affects college students 'concept of marriage and love to some extent. There are many Internet cafes near the school and they are poorly managed. College students are vulnerable to bad videos such as yellow and violence. At the same time, many small hotels near the campus also provide convenience for college students to have premarital sex.

\subsection{Social factors}

The first is the influence of social ethos. With the development of the market economy, some people in the society pursue money worship, and some people blindly pursue a decadent lifestyle and believe that money has love. This directly leads to the current "post-90" female college students in China have the psychological pursuit of material: "money first", marriage must "own the house and car" or through marriage to find rich people to change the fate of similar marriage and other similar ideas have virtually penetrated female college students In the concept of marriage and love; The second is the influence of the media. Nowadays, the media has developed rapidly and has a wide range of influence. The dissemination of magazines, novels, music, film and television, news, and the Internet on marriage and love has a profound influence on college students 'views on marriage and love. Some television and newspaper media, in order to attract people's attention, have explicit descriptions of sexual behavior, extramarital affairs, trials, unmarried cohabitation, unmarried pregnancy, etc., misleading college students to pursue stimulating of the premarital sex life. The over-rendering of perfect love is more likely to mislead college students to fantasize about unrealistic love and pursue the so-called romantic love. "post-90" female college students are the generation that accompanies the growth of the Internet. Their lives are vulnerable to the influence of the Internet, and there will be blind imitation of the concept and behavior of marriage and love promoted by the Internet.

\section{The Changes of the View of the Chinese Marriage and Love}

The Chinese concept of marriage and love has different development under different backgrounds and has undergone many changes.

\subsection{Traditional marriage orientation}

The foundation of society is the family. The foundation of the family is marriage. The basic ritual law of marriage. The Chinese marriage must first and foremost be the ritual law. The ritual law is one of the important contents of the ancient Chinese society's moral system, and the marriage and love under the restrictions of this moral etiquette law are very particular. In the process of performing marriage, there is a series of solemn, serious, and rigorous rituals, The so-called parents 'orders, matchmakers' words, equal in social status, and be faithful to one's husband unto death.

In this ritual society, the purpose of marriage is very clear. When a man and a woman are combined, there is no great relationship for the love. It does not even matter if they are incompatible. As long as the social status is equal, there is a matchmaker as a guarantee, and it can be combined; As long as the couple can help each other, unite and assist and build a home, it is a model household.

\subsection{Changes of the Orientation of the Marriage and Love after the Founding of New China}

Since the founding of New China, there have been four changes in the orientation of marriage and love. New China's first wave of singles began in the 1950s. In the revolutionary era, many people had no time for marriage, and some people were under the orders of their parents to organize marriages. In May 1950, China's first "Marriage Law" was promulgated, followed by a wave of divorces affecting the country. In the late 1970s, the second wave of singles hit. After the "Cultural Revolution" ended, a large number of "knowledge young people" returned to the city, and a group of older single young people, mainly women, quickly gathered in the city. Because many men know that when they go to the countryside, they accept local young women and love to start a family. 
However, young women from large cities are difficult to accept the local male youth, would rather be single than "married." Women generally choose upward social mobility when they marry, so men are also passive in this process.

The "third wave of single people" began around the 1990s, when the trend of thought for freedom and happiness erupted among young men and women, and when the Marriage Law was amended in 1980, the "breakdown of feelings", an indicator that is difficult to quantify, could be used as an appropriate reason for divorce. The number of divorcees has soared. The fourth single wave now appears. The mainstream population is between 28 and 38 years old. The biggest difference from the first and second single wave of "passive singles" is that this group of people has a lot of income, work, fun, and expectations. Marriage experts generally agree that this group of people is not unable to find a spouse in society, but rather prefer to find the best fit for themselves. Compared to the previous "single tide", no one has called the current "single problem" a crisis, and the government has not specifically solved the problem for this group of single men and women.

\section{Measures to guide female college students to establish a correct concept of marriage and love}

The thought of new generation female college students is complex, and the concept of marriage and love is diversified. Being in love and starting a family is a great thing for young people. To do a good job in guiding the young people's concept of marriage and love not only directly affects the healthy development of young people, but also relates to the harmony and stability of society.

\subsection{Strengthening education on traditional ethics}

To absorb the positive factor of Chinese traditional marriage and love culture. With the increasingly close cultural exchanges between the East and the West, modern people's concept of love and marriage has become more and more diverse. People are more and more confused in love and marriage. To this end, we can draw on the positive factors in Chinese traditional culture and learn to inherit the spirit of loyalty, perseverance, sacrifice and dedication, and marital harmony. The cultural knowledge about marriage and love in the Chinese traditional culture after historical precipitation has an indispensable role in improving college students 'bad concept of marriage and love, correcting college students' wrong concept of love and love, and laying the foundation for future marriage and family life.

\subsection{Purification of the social environment}

Purify the social atmosphere and create a good network environment. The prevalence of bad social ethos is actually tempting people to commit bad behavior. To purify the social atmosphere, the whole society needs to work together. The government can hold activities such as "Building a Civilization City", "Sharing the Experience of Marriage and Love”, and "Selection and Publicity of Outstanding Model Couples" to publicize the correct concept of marriage and love. In addition, regular lectures on mental health and correct handling of interpersonal relationships are held to help female college students establish a correct concept of marriage and love. The state can also encourage harmonious relationships by selecting and rewarding "model couples" each year. The Internet has gradually become an indispensable tool for people. Its negative aspect is easy to lead college students into the wrong quagmire. To this end, the state should adopt legislation to regulate the network and form a healthy network environment; The country should also set up network supervision software to remove the negative marriage and love information on the network; Improve the literacy of Internet cafe managers and prevent them from privately spreading unhealthy content of marriage and love.

\subsection{Family education environment}

The family environment plays an extremely important role in the development of children. In addition to meeting children's material needs, parents should also pay attention to the education and training of children's spirit and quality, and must not only pay attention to the achievements of 
children's physical and mental health. It is necessary to pay more attention and guidance to the problem of choosing friends in adolescence. Parents should set a good example for their children in the family environment. The love and mutual concern between parents, the building of a warm atmosphere in the family, and the continuous improvement of parental literacy will affect the child's concept of marriage and love. For the healthy growth of children, parents should constantly absorb new ideas, increase new knowledge, study new educational methods, and promote the healthy development of children's emotions.

\subsection{Cultivating the Right Thinking in Love}

What kind of partner to choose requires the right romantic thinking. There are four most important aspects to the choice of a spouse: morality, appearance, thought, and character. The importance of these four is also in order. The moral character is the most important, the personality is the second most important, and of course there are other aspects such as family, region, etc.. When you first meet a person, you must first consider the previous four. The first is moral character, a person's most important is moral character, the importance of moral character is self-evident; Secondly, appearance is also a very important factor, like is like, hate is hate, your feelings do not need to deceive yourselves. However, if it is between the two, when the first meeting feels okay, it must be carefully considered and carefully decided; Then there is the thought, the two people think together, will produce more communication and resonance, such marriage and love can be more lasting. The ideas here can also refer to academic qualifications, experience, insight, family background, and growth environment. The important thing is that two people must be similar to each other, and they must be in touch with each other. Finally, the character, marriage is the yin and Yang between the two people, complementary character. An optimistic and cheerful person is a good match for a calm and introverted person. An impatient person and a gentle person can also complement each other. What is important is that in ordinary life, they can appreciate each other's strengths and be respectful to each other. Mutual respect, mutual love, mutual appreciation, this is the best realm. If you have the above criteria, you should actively act and take the initiative for your own happiness.

In short, college students 'views on marriage and love are influenced by individuals, schools, society, and mobile phone networks. The view of marriage and love of college students can be molded under the effect of many factors. Using the existing resources to help female college students establish a correct view of marriage and love will help them to have a happy marriage and family life in the future.

\section{References}

[1] 360baike. https://baike.so.com/doc/6351909-6565538.html.

[2] baidu.com. https://jingyan.baidu.com/article/9faa7231b1c0b9473d28cb45.html.

[3] sohu.com. http://www.sohu.com/a/229679087_796130.

[4] http://www.360doc.com/content/16/0306/10/1551761_539807408.shtml.

[5] http://cul.qq.com/a/20170710/025119.htm. 